\title{
Estrogen induces St6gal 1 expression and increases IgG sialylation in mice and patients with rheumatoid arthritis: a potential explanation for the increased risk of rheumatoid arthritis in postmenopausal women
}

Cecilia Engdahl ${ }^{1,2,3^{*}}$ D , Albert Bondt ${ }^{4,5}$, Ulrike Harre ${ }^{1}$, Jasmin Raufer ${ }^{1}$, René Pfeifle ${ }^{1}$, Alessandro Camponeschi ${ }^{2}$, Manfred Wuhrer ${ }^{5}$, Michaela Seeling ${ }^{5}$, Inga-Lill Mårtensson², Falk Nimmerjahn ${ }^{6}$, Gerhard Krönke ${ }^{1}$, Hans U. Scherer ${ }^{4}$, Helena Forsblad-d'Elia ${ }^{2,7}$ and Georg Schett ${ }^{1 *}$

\begin{abstract}
Background: Rheumatoid arthritis (RA) preferentially affects women, with the peak incidence coinciding with estrogen decrease in menopause. Estrogen (E2) may therefore have intrinsic immune-regulatory properties that vanish with menopause. Fc sialylation is a crucial factor determining the inflammatory effector function of antibodies. We therefore analyzed whether E2 affects immunoglobulin G (IgG) sialylation.

Methods: Postmenopausal (ovariectomized) mice were immunized with ovalbumin and treated with E2 or vehicle. Total and ovalbumin-specific lgG concentrations, sialylation, and Fcy receptor expression were analyzed. Postmenopausal women with RA receiving hormone replacement therapy, including E2, or no treatment were analyzed for IgG sialylation. Furthermore, effects of E2 on the expression of the sialylation enzyme $\beta$-galactoside a2,6-sialyltransferase 1 (St6Gal1) were studied in mouse and human antibody-producing cells.

Results: E2 treatment significantly increased Fc sialylation of total and ovalbumin-specific lgG in postmenopausal mice. Furthermore, E2 led to increased expression of inhibitory Fcy receptor llb on bone marrow leukocytes. Treatment with E2 also increased St6Gal1 expression in mouse and human antibody-producing cells, providing a mechanistic explanation for the increase in IgG-Fc sialylation. In postmenopausal women with RA, treatment with E2 significantly increased the Fc sialylation of lgG.

Conclusions: E2 induces anti-inflammatory effector functions in IgG by inducing St6Gal1 expression in antibodyproducing cells and by increasing Fc sialylation. These observations provide a mechanistic explanation for the increased risk of RA in conditions with low estrogen levels such as menopause.
\end{abstract}

Keywords: Rheumatoid arthritis, Female sex, Estrogen, Antibody sialylation

\footnotetext{
* Correspondence: cecilia.engdahl@gu.se; georg.schett@uk-erlangen.de

${ }^{1}$ Department of Internal Medicine 3, Rheumatology and Immunology,

Universitätsklinikum Erlangen, Friedrich Alexander University

Erlangen-Nürnberg, Erlangen, Germany

Full list of author information is available at the end of the article
}

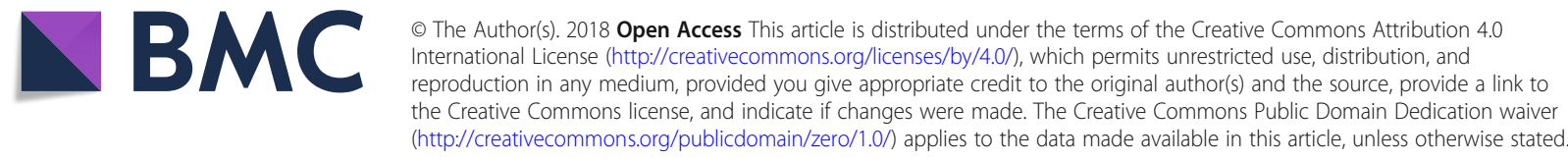




\section{Background}

A person's gender plays a major role in the development of rheumatoid arthritis (RA). Nearly $75 \%$ of patients with RA are women. The reason for the gender imbalance is unclear, but sex hormones are considered to be of pivotal importance. Particularly, the decrease of estrogen in menopause coincides with an increased risk of developing RA [1]. Despite this remarkable association, studies addressing the role of estrogen in the development of RA are scarce [2], and mechanistic studies are virtually absent. Hence, the reason for the preponderance of RA in postmenopausal women remains unclear to date.

RA starts with an autoimmune phase followed by an inflammatory phase [3-5]. Whereas autoimmunity remains clinically silent, inflammation unequivocally leads to symptoms such as pain and swelling. Autoantibodies such as anti-citrullinated peptide antibodies (ACPAs) have a diagnostic, predictive, and prognostic role in RA and can be detected in the preclinical phase several years before the onset of symptoms [6,7]. These observations indicate that B-cell-mediated autoimmunity and autoantibody development is crucial for the onset of inflammation in RA. Data derived from mouse arthritis models support this concept by showing that B cells, autoantibodies, and $F_{c} \gamma$ receptors ( $F c \gamma R s$ ), which mediate the effector function of autoantibodies, are necessary for the development of arthritis [8-10].

Besides their role in antigen recognition, antibodies regulate effector cell activation through their constant Fc regions, which bind to FcyRs and activate monocytes/ macrophages. Antibodies bear one or several carbohydrate chains, or glycans. Glycan at the Asn297 position at the Fc part of IgG regulates binding capability to Fc $\gamma$ Rs [11-13]. This glycan is composed of a conserved heptamer that consists of $\mathrm{N}$-acetylglucosamine and mannose residues, which can be extended by fucose, galactose, and finally sialic acids. The composition of the IgG-Fc glycosylation, in particular without terminal sialic acids, determines effector cell activation and hence the inflammatory properties of antibodies [14]. Low sialylation of Asn297 enhances the proinflammatory activity [15-19], whereas the attachment of terminal sialic acid residues mediates anti-inflammatory effects [20]. Importantly, it has been shown that the transition from asymptomatic autoimmunity to RA is associated with a change in the sialylation status of antibodies [20, 21].

Population studies have revealed that IgG-Fc galactosylation and sialylation are higher in premenopausal women than in men but decrease with age [22, 23]. During pregnancy, when women are protected from RA, IgG-Fc sialylation as well as galactosylation increase [24, 25], and then reverse within 3 months postdelivery, when RA risk is higher [25]. Estrogen has been shown to decrease galactosylation of human IgG in healthy individuals [26], which may explain the increased risk of RA in postmenopausal women. Whether estrogen influences IgG sialylation has not been investigated yet. In the present study, we show that estrogen influences the presence of sialic acid on the Fc glycan of IgG, both in postmenopausal mice challenged by immunization and in postmenopausal women with RA. This effect is based on estrogen-mediated induction of $\beta$-galactoside $\alpha 2,6$-sialyltransferases 1 (St6gal1) in plasmablasts, the enzyme that adds sialic acid residues to IgGs. Hence, decrease in estrogen in menopause creates a proinflammatory state characterized by low IgG sialylation and increased risk of developing arthritis.

\section{Methods}

\section{Animals and treatments}

Female C57BL/6 mice were kept under standard conditions with standard chow and tap water ad libitum. The study was approved by the ethics committees of the Government of Mittelfranken (Germany) and the University of Gothenburg (Sweden). To avoid confounding endogenous sex hormone effects and to mimic a postmenopausal state, mice were ovariectomized (OVX) or shamoperated at 10 weeks of age. Estrogen (17 $\beta$-estradiol, E2) treatment was carried out with slow-release subcutaneous pellets (Innovative Research of America, Sarasota, FL, USA) containing E2 $(0.83 \mu \mathrm{g} /$ day $)$ or placebo. Treatment of mice with such doses is known to result in serum E2 levels of approximately $60 \mathrm{pg} / \mathrm{ml}$ [27]. In mice, normal serum levels of E2 vary between 25 and $50 \mathrm{pg} / \mathrm{ml}$ in diestrus and between 150 and $200 \mathrm{pg} / \mathrm{ml}$ in estrus [28]. Thus, the dose used in this study resulted in physiological serum E2 levels. Treatment efficiency was confirmed by the weighing of the uterus.

\section{Immunization with ovalbumin}

Mice were subcutaneously immunized with $100 \mu \mathrm{g}$ of ovalbumin (OVA) (Sigma-Aldrich, St. Louis, MO, USA) emulsified in complete Freund's adjuvant (Sigma-Aldrich). Followed with a booster injection the same way including $100 \mu \mathrm{g}$ of OVA (Sigma-Aldrich) emulsified in incomplete Freund's adjuvant after 14 days. Serum was taken before OVA immunization, 10 days after initial immunization (day 22), and 10 days after boost (day 38).

\section{Hormone replacement therapy}

Postmenopausal women with RA $(N=49)$ aged 45-65 years were included in a 2-year, randomized, single-blind, controlled study [29]. Patients had active disease with at least two of the following criteria: at least six painful joints, at least three swollen joints, erythrocyte sedimentation rate $\geq$ $20 \mathrm{~mm} / \mathrm{h}$, and C-reactive protein $\geq 10 \mathrm{mg} / \mathrm{L}$. Patients 
fulfilled the American Rheumatism Association 1987 criteria for RA [30]. Women in the hormone replacement therapy (HRT) group were given continuous treatment with $2 \mathrm{mg}$ of E2 plus $1 \mathrm{mg}$ of norethisterone acetate daily. All patients provided informed consent, and the ethics committee at the University of Gothenburg (Sweden) approved the study.

\section{Serum measurements}

In the sera from the human HRT study, ACPA were evaluated by enzyme-linked immunosorbent assay (ELISA) (Orgentec Diagnostika, Mainz, Germany). In mice, IgGs were measured using commercially available kits (Bethyl Laboratories, Montgomery, TX, USA). OVA-specific IgG were measured with an in-house ELISA, plates were coated with $100 \mu \mathrm{g} / \mathrm{ml}$ OVA (Sigma-Aldrich), incubated with sera (diluted 1:5000), and detected with horseradish peroxidase (HRP)-conjugated polyclonal rabbit antimouse IgG (Dako/Agilent Technologies, Waldbronn, Germany). For evaluation of the affinity properties of antibodies, potassium thiocyanate (Sigma-Aldrich) was added in various doses. For measurement of sialic acid residues on IgG or OVA-specific IgG, biotinylated Sambucus nigra lectin (Vector Laboratories, Burlingame, CA, USA) and streptavidin-HRP (R\&D Systems, Minneapolis, MN, USA) were used for detection.

\section{Isolation of OVA-specific antibodies}

OVA-specific antibodies were captured from serum of OVA-immunized mice. Protein G-isolated total IgG was dialyzed in sodium phosphate dibasic and enriched over OVA-coupled Sepharose 4B beads (Sigma-Aldrich), washed with $\mathrm{NaCl}$ four times, and eluted with lectin buffer. ELISA confirmed enrichment of OVA-specific IgG.

\section{Mass spectrometric analysis for Fc glycans}

For the analysis of Fc glycosylation, the IgG eluates were subjected to tryptic digestion by adding $600 \mathrm{ng}$ of tosyl phenylalanyl chloromethyl ketone-treated trypsin (Merck, Kenilworth, NJ, USA) in $40 \mu \mathrm{l}$ of ammonium bicarbonate buffer followed by overnight incubation at $37^{\circ} \mathrm{C}$. Digested IgG was separated and analyzed using a Dionex UltiMate 3000 UHPLC system (Thermo Fisher Scientific, Waltham, MA, USA) coupled to a maXis Impact HD quadrupole-time-of-flight mass spectrometer (MS) (Bruker Daltonics, Billerica, MA, USA). Details are described in Additional file 1: Supplementary methods. The quality of mass spectra was evaluated on the basis of total intensities per glycopeptide cluster. Analyte curation was performed using the signal-to-noise ratio, isotopic pattern quality, and observed mass-tocharge ratio $(\mathrm{m} / \mathrm{z})$ deviation as obtained after data (pre-)processing with LacyTools [31]. Following extraction of tryptic glycopeptides by a C18 solid-phase extraction trap column (Dionex Acclaim PepMap 100; Thermo Fisher Scientific), separation was performed with a Supelco Ascentis Express C18 nano-LC column (Sigma-Aldrich) conditioned at $900 \mathrm{nl} / \mathrm{min}$ with $0.1 \%$ trifluoroacetic acid (mobile phase A), after which the following gradient of mobile phase A and 95\% acetonitrile (mobile phase B) was applied: 0 minutes $3 \% \mathrm{~B}$, 2 minutes $6 \%$ B, 4.5 minutes $18 \%$ B, 5 minutes $30 \%$ B, 7 minutes $30 \%$ B, 8 minutes $1 \%$ B, and 11 minutes $1 \%$ B. The ultraperformance LC was interfaced to the MS with a CaptiveSpray electrospray ionization source and nanoBooster (Bruker Daltonics). Mass spectra were recorded from $m / z 550$ to 1800 at a frequency of $1 \mathrm{~Hz}$. Quadrupole ion energy and collision energy of the MS were set at 2 and $5 \mathrm{eV}$, respectively. The total analysis time per sample was 13 minutes. Detailed calculations are provided in Additional file 1: Supplementary methods.

\section{Cell preparation and flow cytometry}

Cell suspensions were obtained from spleen and bone marrow and stained for surface markers after erythrolysis, fixation, and permeabilization (eBioscience, San Diego, CA, USA). Analyses were performed using a Gallios flow cytometer (Beckman Coulter Life Sciences, Indianapolis, IN, USA) and Kaluza Flow Analysis software (Beckman Coulter Life Sciences). The following fluorochrome- or biotinconjugated antimouse antibodies and reagents were used: allophycocyanin (APC)-conjugated anti-CD267 (transmembrane activator calcium modulator and cyclophilin ligand interactor), fluorescein isothiocyanate (FITC)-conjugated anti-B220, and FITC-conjugated anti-CD11b (all from eBioscience); phycoerythrin (PE)-conjugated anti-CD138 and PE-cyanine 7 (Cy7) conjugated anti-CD3, Pacific Blue F4/80, PE-Cy7 Ly6G, and PE-FcyRIII (CD16) (all from BioLegend, San Diego, CA, USA); APC-conjugated Fc $\gamma$ RI (CD64), FcyRIIB, and FcyRIV (self-made); Alexa Fluor 488conjugated OVA-A488 (Thermo Fisher Scientific); antiSt6gal1) (C) (IBL International/Tecan, Morrisville, NC, USA); and normal rabbit IgG (isotype-matched control antibody) (Thermo Fisher Scientific).

\section{Mouse B-cell proliferation}

Splenic B cells were isolated by CD43 depletion using MACS technology (Miltenyi Biotec, Bergisch Gladbach, Germany). The cells were stimulated with lipopolysaccharide (LPS) (Sigma-Aldrich) and cultured for 48 hours to develop them into plasmablasts. The medium was then changed to serum-free medium with no estrogen or $10^{-8} \mathrm{M} 17 \beta$-estradiol (E2) (Sigma-Aldrich) for the last 24 hours. Blocking antibodies toward IL-22 (Poly5164; BioLegend) and tumor necrosis factor (TNF)- $\alpha$ (UltraLEAF anti-TNF- $\alpha$, MP6-XT22; BioLegend) were added. Seventy-two hours after initial seeding and 24 hours after 
change in medium, supernatants were collected and cells were isolated for RNA analyses.

\section{Plasma cell isolation}

$\mathrm{CD} 138^{+}$splenic plasmablasts were isolated using MACS technology (Miltenyi Biotec) from OVX OVA-immunized mice treated with estrogen or placebo. The purified cells were isolated for RNA analyses.

\section{Human B-cell proliferation}

Human B cells were purified from peripheral blood mononuclear cells using immunomagnetic beads (Dynal ${ }^{\odot}$ B Cell Negative Isolation Kit; Thermo Fisher Scientific). The cells were stimulated with TLR-9 agonist cytosinephosphate-guanine (CpG) oligodeoxynucleotide 2006 (InvivoGen, San Diego, CA, USA), goat anti-human IgA/ IgG/IgM $\mathrm{F}\left(\mathrm{ab}^{\prime}\right)_{2}$ fragments (Jackson ImmunoResearch Laboratories, West Grove, PA, USA), and human recombinant IL-2 (R\&D Systems), then cultured for 5 days to develop them into plasmablasts. After 5 days, medium was changed to no estrogen or $10^{-8} \mathrm{M} 17 \beta$-estradiol (E2) (Sigma-Aldrich). Seven days after initial seeding and 48 hours after medium change, cells were isolated for RNA analyses.

\section{RT-PCR}

Total RNA was extracted using an RNeasy kit (Qiagen) and transcribed into complementary DNA using oligo(dT) primers and MuLV reverse transcriptase (Roche Diagnostics, Indianapolis, IN, USA). qRT-PCR was performed with SYBR Green I dTTP (Eurogentec, Liège, Belgium) or the Applied Biosystems StepOnePlus ${ }^{\text {TM }}$ RealTime PCR system (Thermo Fisher Scientific) using an assays-on-demands primer and probe set. The gene expression values were normalized to those of the control gene encoding $\beta$-actin and $18 \mathrm{~S}$. Primer sequences are described in Additional file 1: Supplementary methods.

\section{Statistical analysis}

Statistical analyses were performed using Prism software (GraphPad Software, La Jolla, CA, USA). Two separate groups were compared with unpaired Student's $t$ tests. One-way analysis of variance followed by Bonferroni multiple-comparisons tests were performed for selected columns. Outliers were eliminated using Grubbs' test. The correlation was investigated with Spearman's correlation coefficients. Data are presented as mean \pm SEM or as scatterplots, and $p<0.05$ was considered significant.

\section{Results}

Effects of menopausal state and E2 treatment on antibody responses to ovalbumin immunization

To understand the effect of estrogen on the humoral immune response, we immunized mice with OVA. Prior to immunization, mice were either sham-operated or OVX with or without subsequent treatment with E2, reflecting HRT or estrogen deficiency, respectively. As expected, OVA immunization increased total IgG and OVA-specific IgG (Fig. 1a and b). E2 treatment increased total IgG2b and IgG1 levels, but no differences were found in the development of OVA-specific IgG, suggesting that E2 does not influence antibody titers after immunization. Also, the affinity of OVA-specific antibodies was not affected by estrogen status (Fig. 1c).

\section{Effects of menopausal state and E2 treatment on IgG sialylation}

Estrogen treatment increased terminal sialic acid residues of total IgG (Fig. 1d). Even more interesting, this increase was also seen in OVA-specific IgG (Fig. 1e), whereas ovariectomy itself induced a significant decrease of sialylation of OVA-specific IgG. Mass spectrometric analysis of purified OVA-specific IgG2 showed significantly lower sialic acid content in OVX mice, whereas E2 treatment rescued IgG2 sialylation (Fig. 1f). In contrast, no difference was found in OVA-depleted IgG2, indicating that estrogen determines the sialylation of newly formed antigen-specific antibodies. Galactose, which is positioned proximal to sialic acids was much less affected by E2 (Fig. 1f), although a trend $(p=0.08)$ toward higher galactosylation was found in OVA-specific IgG2 after E2 treatment. Overall, these results indicate that estrogen status regulates the sialic acid content of newly formed IgG. Conversely, E2 deficiency suppresses the sialylation of IgGs. These observations support the hypothesis that E2 could regulate IgGmediated effector functions.

\section{Effects of menopausal state and E2 treatment on FcyR expression}

We next determined estrogen regulation of $F c \gamma R$ expression in OVA-challenged mice treated with E2. E2 status affects B-cell and plasma cell frequency; therefore, the mean fluorescence intensity was used to determine the expression quantity of each FcyR. We observed that in the bone marrow, estrogen significantly increased the expression of the inhibitory FcyRIIb in plasmablasts, monocytes, and neutrophils (Fig. 2a). In the spleen, similar effects could be observed only with neutrophils (Fig. 2b). Expression of activating FcyRIII and FcyRIV was not affected by either ovariectomy or E2 treatment (Fig. 2c and d). Furthermore, OVA-specific IgG subclass composition was not significantly affected by ovariectomy or E2 treatment, although a trend toward lower IgG2a and IgG2b levels was found after ovariectomy (Additional file 2: Supplementary Figure 1). 


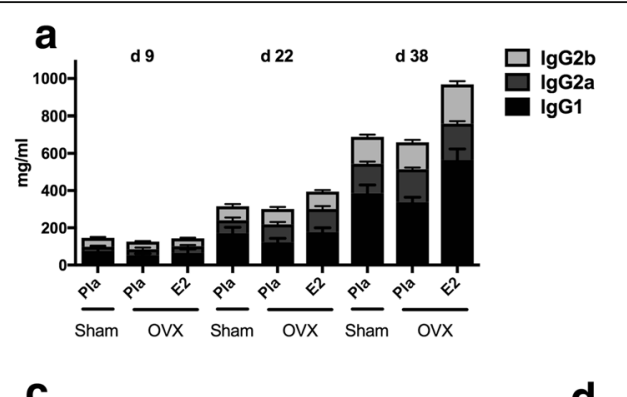

C

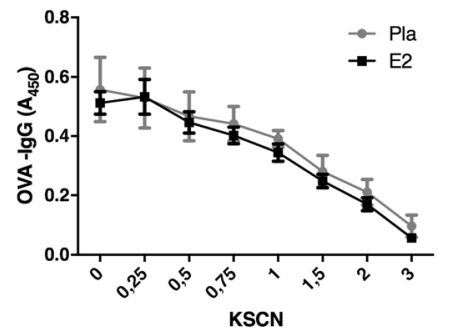

d
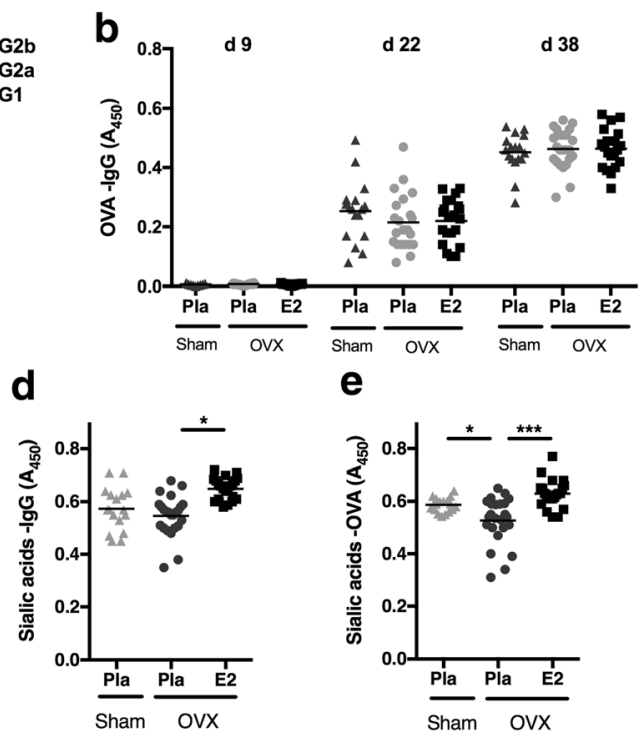

e

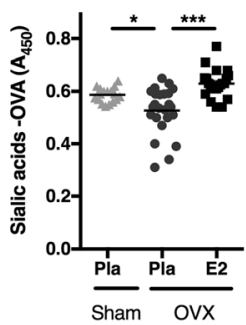

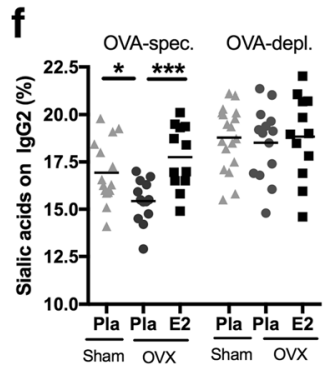

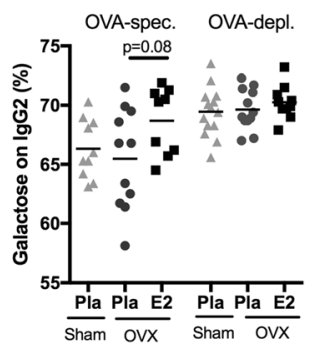

Fig. 1 Estrogen influences immunoglobulin G (lgG) sialylation. Mice were ovariectomized (OVX) at 3 months of age, followed by insertion of slow-release treatment pellets with placebo (Pla) or estrogen (E2; $0.83 \mu \mathrm{g} /$ day). Ten days after ovariectomy, the animals were immunized with ovalbumin (OVA), and 14 days later, they were boostered. Serum was taken at day 9 (d9) before immunization, day 22 (d22) after immunization, and day 38 (d38) at termination after immunization and boostering. a Total lgG concentrations: significant induction in all treatment groups after immunization (day 9-day 22) and after boostering (day 22-day 38) for all IgG subtypes. Data are mean \pm SEM $(n=11-13)$. b Concentration of ovalbumin-specific IgG (OVA-IgG) $(n=17-24)$. c Titers of ovalbumin-specific IgG measured at termination $(n=10-12)$. $\mathbf{d}$ Concentration of sialic acids on total lgG measured at termination ( $n=17-24)$. e Concentration of sialic acids on OVA-specific lgG measured at termination $(n=17-24)$. $\mathbf{f}$ Mass spectrometry-based analysis of sialic acids and galactose on lgG-Fc of OVA-specific (OVA-spec) and OVA-depleted (OVA-dep) lgG2 measured at termination ( $n=12-14$ ). Values are indicated on a scatter dot plot with mean indicated by a bar. Statistical analysis with analysis of variance followed by the Bonferroni multiple-comparisons test for selected time points. ${ }^{*} p<0.05,{ }^{* * *} p<0.001$

\section{E2 increases the expression of $\beta$-galactoside $\alpha 2,6$ - sialyltransferase 1 in plasmablasts}

To explain the effects of E2 on IgG Fc sialylation, we analyzed the expression of St6gal1, the enzyme responsible for the attachment of sialic acid residues to IgG, in plasmablasts. mRNA was isolated from splenic plasmablasts purified from postmenopausal mice (OVX) with and without E2 treatment that had been challenged by OVA immunization. The identity of the plasmablasts was confirmed by measuring mRNA expression of the plasma cell-specific marker Blimp1 (Fig. 3a). Expression of St6gal1 was significantly upregulated by E2. In contrast, expression of $\beta$-1,4-galactosyltransferase 1 (B4galt1), which is responsible for IgG galactosylation, was hardly affected. St6gal1 protein expression of plasmablasts was further investigated using flow cytometric analysis. E2 treatment showed significantly higher expression of St6gal1 in total splenic plasmablasts (Fig. 3b) as well as in OVA-specific plasmablasts (Fig. 3c).

To determine whether E2 directly affects St6gal1 expression or whether this effect is mediated by cytokines, we stimulated naive splenic B cells by LPS to induce plasmablast differentiation. Blimp1 mRNA was upregulated and IgG production was increased, confirming plasmablast differentiation (Fig. 3d). E2 treatment upregulated IgG levels compared with E2 restriction. As expected, St6gal1 mRNA was significantly upregulated upon E2 treatment, whereas no effect was seen for B4galt1 (Fig. 3e). Cytokines such as TNF- $\alpha$, which is regulated by E2 [32], as well as IL-22, have been shown to influence IgG glycosylation [20, 33]. We therefore blocked TNF- $\alpha$ and IL-22 to test whether cytokine inhibition influences the effect of E2 on ST6gall expression. However, upregulation of St6gal1 was still evident 

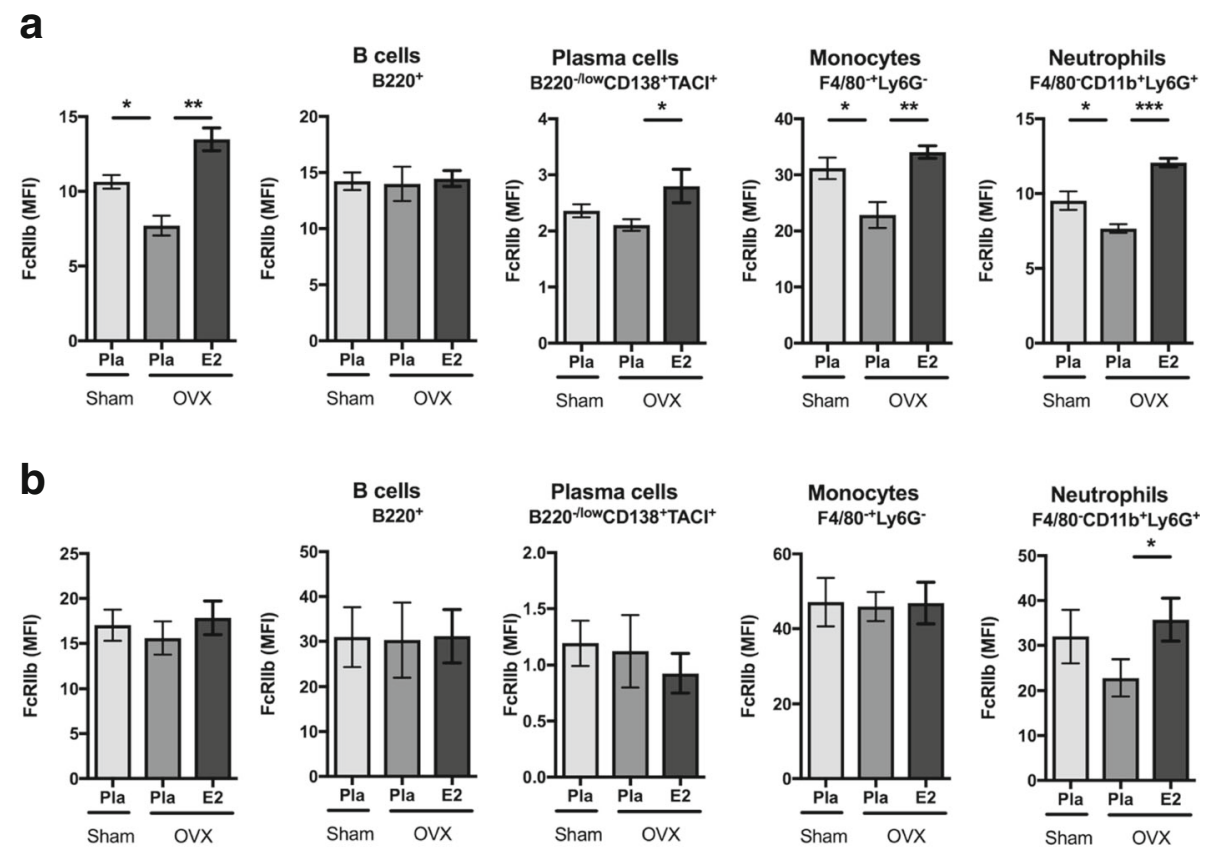

C

d
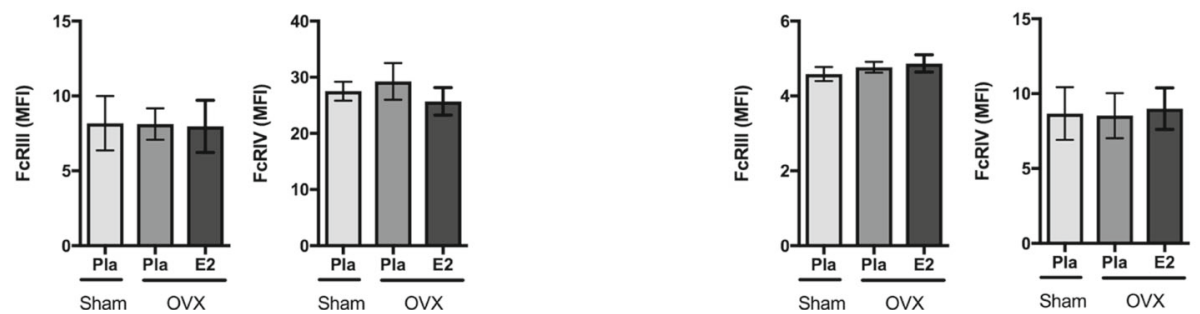

Fig. 2 Effects of estrogen on Fcy receptor expression. Ovariectomized (OVX) mice at 3 months of age followed by insertion of slow-release treatment pellets with placebo (Pla) or estrogen (E2; $0.83 \mu \mathrm{g} /$ day). Ten days after ovariectomy, the animals were immunized with ovalbumin (OVA), and 14 days later, they were boostered. On day 38, mean fluorescence intensity (MFI) of Fc receptors (FcRs) was quantified using flow cytometry in all leukocytes as well as B cells, plasmablasts, monocytes, and neutrophils. Expression of inhibitory FcyRllb in (a) bone marrow cells and (b) spleen cells. Expression of stimulatory FcyRIII and FcyRIV in (c) bone marrow cells and (d) spleen cells. Groups are presented with a bar indicating mean \pm SEM $(n=6-7)$. Statistical analysis with analysis of variance followed by the Bonferroni multiple-comparisons test for selected time points. ${ }^{*} p<0.05,{ }^{* *} p<0.01,{ }^{* * *} p<0.001$

after blocking with anti-TNF- $\alpha$ and anti-IL-22 antibodies (Fig. 3e), suggesting that E2 upregulation of St6gal1 is independent of TNF- $\alpha$ and IL-22.

\section{E2 treatment in patients with RA increases antibody sialylation}

To confirm the relevance of the above-described findings for patients with RA, we examined serum samples of 49 postmenopausal women with RA treated with or without HRT [29, 34, 35]. In a previous trial, HRT treatment was shown to reduce disease activity of RA and to increase bone mineral density. On the basis of a total of seven ACPA-negative patients (three in the HRT-treated group and four in the control group), there was no difference in ACPA titers between patients receiving HRT or not receiving HRT (Fig. 4a). For the next investigations, we concentrated on ACPA-positive patients and found that IgG galactosylation and sialylation in the 42 ACPApositive patients were increased in the HRT-treated patients in both the Fc regions of IgG1 (Fig. 4b and c) and IgG2/3 (Additional file 3: Supplementary Figure 2a and b). Fucose residues were not altered in the Fc regions of IgG1 (Fig. 4d) or IgG2/3 (Additional file 3: Supplementary Figure 2c). These data indicate that E2 treatment increases sialic acid content on IgG-Fc tails in postmenopausal women with RA. The increase in IgG sialylation and galactosylation in individual patients over time is depicted in Additional file 4: Supplementary Figure 3. Furthermore, when correlating the degree of IgG sialylation and galactosylation to serum E2 levels, we found a significant positive correlation, adding further evidence that E2 can regulate the effector function of IgGs in humans 


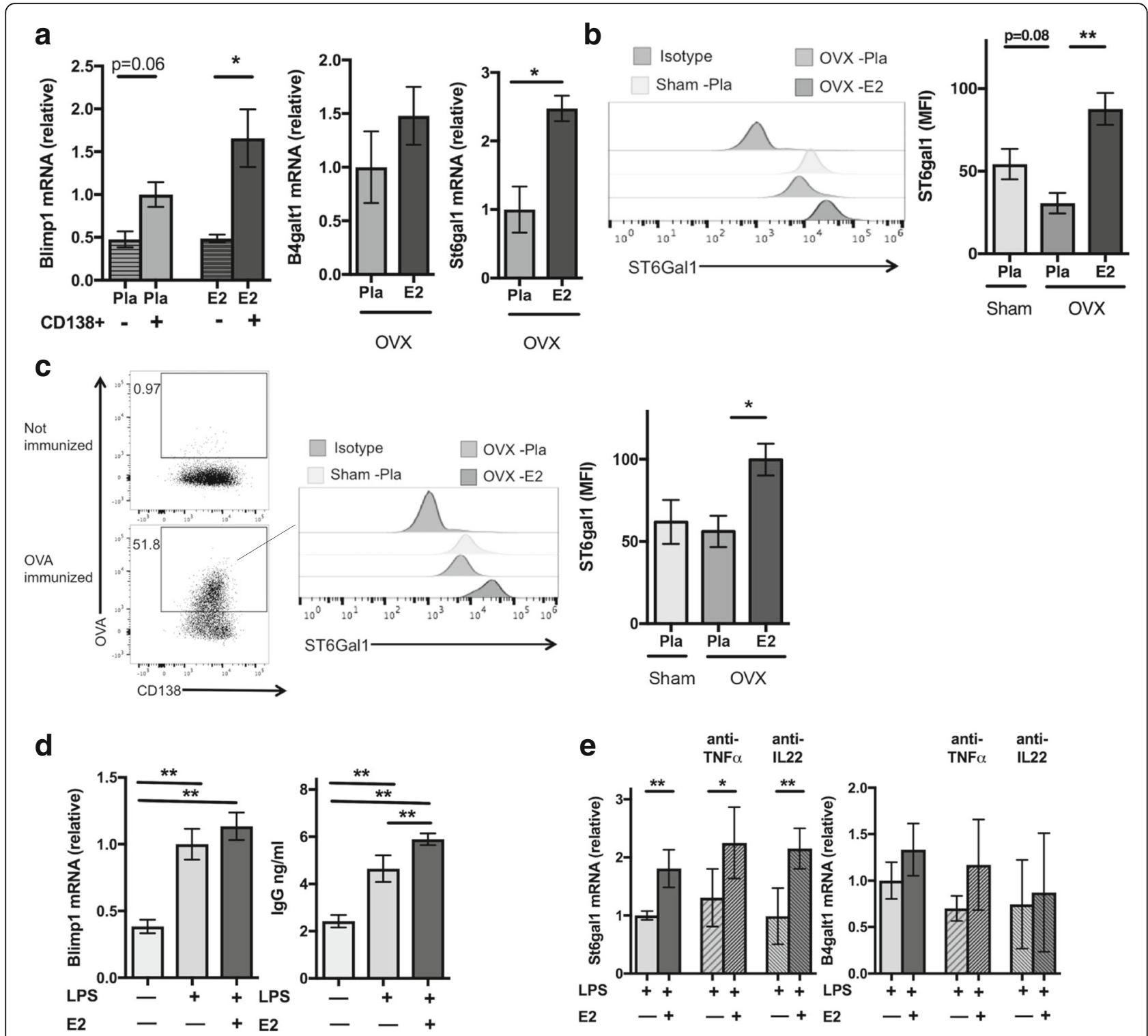

Fig. 3 Estrogen affects expression of the sialylation enzyme in plasmablasts. Mice were ovariectomized (OVX) at 3 months of age, followed by insertion of slow-release treatment pellets with placebo (Pla) or estrogen (E2; $0.83 \mu \mathrm{g} /$ day). Ten days after ovariectomy, animals were immunized with ovalbumin $(\mathrm{OVA})$, and 14 days later, they were boostered. a Expression of Blimp1, $\beta$-1,4-galactosyltransferase 1 (B4galt1), and $\beta$-galactoside $\alpha 2,6$-sialyltransferase 1 (St6gal1) in CD138-sorted plasmablasts on day $38(n=5-6)$. Statistical analysis was performed with Student's $t$ test. b Flow cytometry-based quantification of mean fluorescence intensity (MFI) of St6Gal1 expression of plasmablasts on day $38(n=10-14)$. Statistical analysis was performed with analysis of variance (ANOVA) followed by the Bonferroni multiple-comparisons test. c Flow cytometry-based quantification of MFI St6Gal1 expression of OVA-specific plasmablasts $(n=10-14)$. Statistical analysis was performed with ANOVA followed by the Bonferroni multiple-comparisons test. d Immunoglobulin G in supernatant and expression of Blimp1, in CD43-negative splenic cells stimulated with lipopolysaccharide (LPS) for 72 hours for development into plasmablasts. For the last 24 hours, the cells were stimulated with the presence (+) of estrogen (E2) $10^{-8}$ or absence (-) of E2. e Expression of B4galt1, and St6gal1 in CD43-negative splenic cells stimulated with lipopolysaccharide (LPS) for $72 \mathrm{~h}$ for development into plasmablasts. For the last $24 \mathrm{~h}$, the cells were stimulated with the presence (+) of estrogen (E2) 10- 8 or absence (-) of E2. Anti-tumor necrosis factor (TNF)-a or antinterleukin (IL)-22 antibodies were also added as indicated. Statistical analysis was performed with Student's $t$ test $(n=5-7)$. ${ }^{*} p<0.05$, ${ }^{*} p<0.01$. Data are shown as mean \pm SEM. mRNA Messenger RNA

(Additional file 5: Supplementary Figure 4a and b). In addition, IgG sialylation and galactosylation showed a significant inverse correlation with RA disease activity as measured by Disease Activity Score [29] (Additional file 5: Supplementary Figure 4c and d).
E2 increases St6gal1 expression in human plasmablasts

Finally, and on the basis of data obtained from the human cohort, we analyzed whether E2 can induce St6gal1 expression in human plasmablasts. To test this, we isolated human B cells from healthy control subjects, differentiated 
a

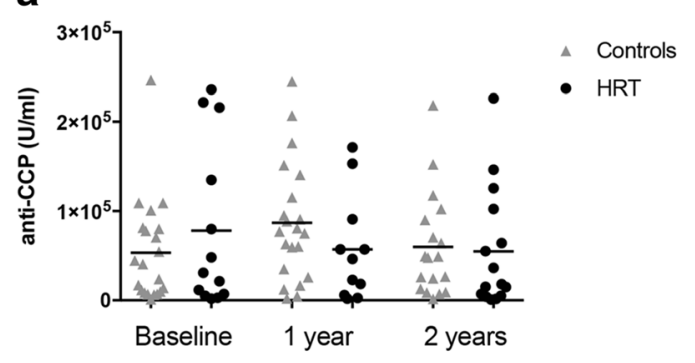

C

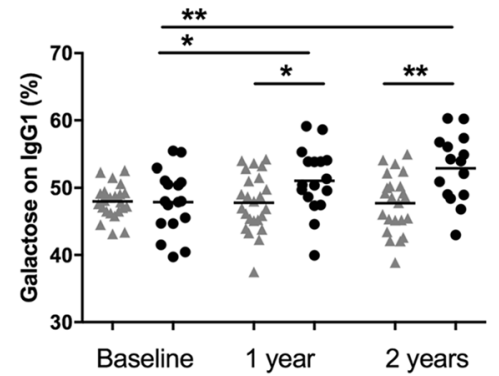

e

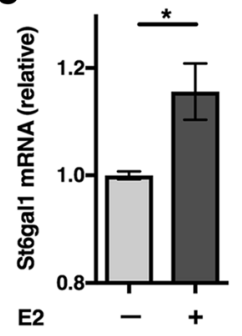

b

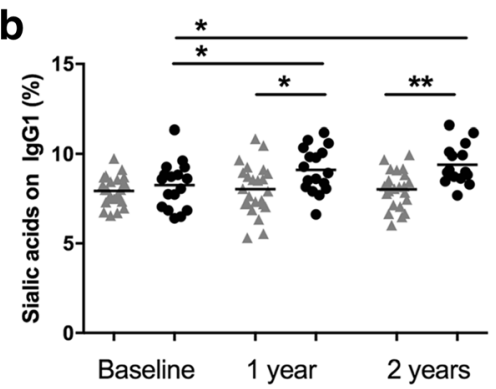

d

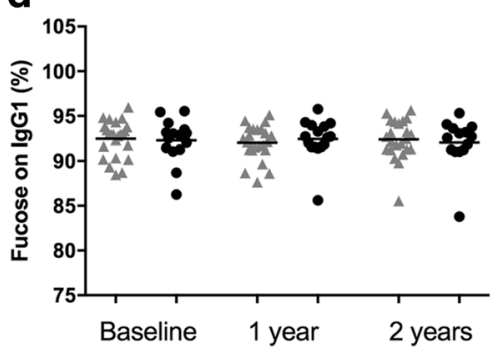

Fig. 4 Estrogen increases immunoglobulin $\mathrm{G}$ (lgG) glycosylation in postmenopausal patients with rheumatoid arthritis (RA). Forty-nine postmenopausal women with active RA in a randomized controlled trial were receiving either hormone replacement therapy (HRT) or no HRT. Serum samples were taken at baseline and after 1 year and 2 years of treatment. a Anticitrullinated protein antibody concentrations ( $n=20-29 ; 7$ anti-cyclic citrullinated peptide [anti-CCP]-negative patients were excluded from further studies). Mass spectrometry-based analysis of (b) sialic acids, (c) galactose, and (d) fucose on the Fc portion of IgG. Statistical analysis was performed with $t$ tests at selected time points, as well as an investigation over time in HRT-treated individuals. ${ }^{*} p<0.05,{ }^{* *} p<0.01(n=17-25)$. Groups are presented with a bar indicating mean with SEM. e Messenger RNA (mRNA) expression of St6gal1 and B4galt1 from B cells isolated from peripheral blood collected from healthy donors and stimulated with CpG, interleukin-2, and goat antihuman $\lg \mathrm{A} / \operatorname{lgG} / \operatorname{lgM~F}\left(\mathrm{ab}^{\prime}\right)_{2}$ fragments for 5 days to induce plasmablast differentiation. For the last 48 hours, the cells were stimulated with the presence (+) of estrogen (E2) $10^{-8}$ or absence (-) of E2. Statistical analysis was performed with Student's $t$ test. ${ }^{*} p<0.05(n=3)$. Values are indicated as scatter dot plots with means indicated with a bar

them into plasmablasts, and added E2 for the last 48 hours. E2 significantly upregulated mRNA expression of St6gal1 in the human plasmablasts, whereas no such effect was observed for B4galt1 (Fig. 4e). Hence, E2 also induces St6gal1 and IgG sialylation in humans.

\section{Discussion}

In the present study, we show that E2 influences IgG glycosylation, especially the sialylation of IgG, by upregulating the key enzyme St6gal1 in plasmablasts. Deficiency of E2, like in menopause, leads to decreased antibody sialylation and to a proinflammatory IgG pattern, which could influence the onset of RA and may explain the increased risk of RA in postmenopausal women. However, E2 administration increased sialylation of IgG, shifting the antibody effector function to a more regulatory anti-inflammatory pattern, which is supported by a negative correlation between the degree of IgG sialylation and galactosylation with RA disease activity.

In RA, it is well established that autoantibody formation precedes the symptomatic inflammatory phase of the disease. Factors that shift asymptomatic autoimmunity to inflammation are therefore of key interest in understanding the onset of disease [36]. The sialylation status of autoantibodies seems to play a crucial role in this shift. Low-level IgG sialylation promotes progression to inflammation, whereas high-level sialylation promotes suppression of symptoms [20]. Our results indicate that estrogen affects the pathogenicity of the antibodies, mainly via regulation of IgG-Fc sialylation. Hence, 
higher levels of E2 create an anti-inflammatory environment by inducing St6gal1, resulting in a higher degree of antibody sialylation. In accordance, the sharp decrease of estrogens in menopause is supposed to switch this environment to low sialylation and a proinflammatory pattern.

In contrast to the findings regarding sialylation, we did not detect any significant effect of E2 on galactosylation in mice or on the expression of B4galt1, the enzyme mediating galactosylation, in mouse and human antibody-producing cells. Nonetheless, in postmenopausal patients with RA, treatment with E2 increased not only sialylation but also galactosylation of IgG. Similarly, we observed strong correlations of IgG-Fc galactosylation and levels of estrogen in the postmenopausal patients with RA. These findings are in accordance with previous results in healthy individuals showing that E2 regulates galactosylation [26]. Because galactosylation is a prerequisite for sialylation at the Asn297 site of IgG, an effect of E2 on galactosylation might further strengthen the overall E2-induced glycosylation pattern of human IgG.

E2 effects on B-cell [37-39] and plasma cell differentiation $[40,41]$ have been reported previously, but functional consequences on the pattern of plasma cell-mediated antibody production have so far been undetermined. On one hand, regulation of St6gal1 by E2 suggests that the overall effect of E2 on the effector pathways of adaptive immunity is a regulatory one and that loss of E2 induces a proinflammatory environment by altering effector functions of antibodies. On the other hand, E2 did not have any consistent effect on specific antibody levels and affinity, suggesting that the key factor by which E2 regulates inflammatory responses is indeed its influence on IgG glycosylation. Future studies need to be done to test whether estrogen treatment in postmenopausal women stimulates St6gal1 in $\mathrm{B}$ cells and plasmablasts.

\section{Conclusions}

The data derived from the present study provide a basis for a molecular concept that could explain why susceptibility to RA changes during a woman's life and specifically increases in menopause. E2 appears to be a protective factor rather than a risk factor in triggering inflammation in arthritis by inhibiting the proinflammatory effector functions of autoantibodies. Higher rates of flares of RA with the decrease of sex hormones after pregnancy [42], as well as the accumulation of flares in the second low-estrogen phase of the menstrual cycle [43], also support this concept. Treatment with E2 may therefore have a beneficial effect in some patients with RA, particularly in those with imminent RA displaying autoantibodies and initial symptoms such as pain, with a high risk of progressing to clinical RA.

\section{Additional files}

Additional file 1: Supplementary methods. (DOCX $131 \mathrm{~kb})$

Additional file 2: Supplementary Figure 1. Estrogen effects on

ovalbumin-specific lgG subclasses. Ovariectomized mice received slow-release treatment pellets with placebo (Pla) or estrogen (E2; $0.83 \mu \mathrm{g} /$ day). Ten days after ovariectomy, the animals were immunized with ovalbumin (OVA), and 14 days later, they were boostered. On day 38, lgG subclasses of ovalbumin (OVA)-specific lgG were measured. A scatterplot with means indicated by lines is shown ( $n=9-11$ mice per group). Statistical analysis was performed with analysis of variance followed by the Bonferroni multiple-comparisons test. (PDF $1088 \mathrm{~kb}$ )

Additional file 3: Supplementary Figure 2. Estrogen treatment increases lgG-Fc sialylation and lgG-Fc galactosylation in postmenopausal patients with rheumatoid arthritis (RA). Forty-nine postmenopausal women with active RA were included in a randomized controlled trial receiving either hormone replacement therapy (HRT) or no HRT. Serum samples were taken at baseline and after 1 year and 2 years of treatment. Mass spectrometry-based analysis of (a) sialic acids, (b) galactose, and (c) fucose of the Fc portion of $\lg G 2 / 3$ $(n=17-25)$. Statistical analysis was performed with $t$ tests at selected time points, as well as in an investigation over time in individuals who received HRT. * $p<0.05,{ }^{* * *} p<0.001$. (PDF $1915 \mathrm{~kb}$ )

Additional file 4: Supplementary Figure 3. Effects of estrogen on lgGFc sialylation and IgG-Fc galactosylation in individual patients. Analysis of (a, b) IgG-Fc sialylation and (c, d) IgG-Fc galactosylation in postmenopausal women with active rheumatoid arthritis (RA) randomized to receive hormone replacement therapy $(\mathrm{HRT})(\mathbf{a}, \mathbf{c})$ or no HRT $(\mathbf{b}, \mathbf{d})$ in a controlled trial. Each line represents one patient. (PDF $2784 \mathrm{~kb}$ )

Additional file 5: Supplementary Figure 4. Correlation between lgG glycosylation and estrogen levels and disease activity. Correlation between (a) lgG-Fc sialylation and (b) lgG-Fc galactosylation (y-axis) and estrogen level ( $x$-axis). Correlation between (c) lgG-Fc sialylation and (d) lgG-Fc galactosylation $(y$-axis) and Disease Activity Score (DAS) (x-axis). Spearman's correlation coefficients ( $r$ ) and $p$ values are shown. (PDF $2188 \mathrm{~kb})$

\section{Abbreviations}

ACPA: Anticitrullinated peptide antibodies; APC: Allophycocyanin; B4galt1: $\beta$ 1,4-Galactosyltransferase 1; Cy7: Cyanine 7; E2: Estrogen; ELISA: Enzyme-linked immunosorbent assay; FcyR: Fcy receptor; FITC: Fluorescein isothiocyanate; HRP: Horseradish peroxidase; HRT: Hormone replacement therapy; LPS: Lipopolysaccharide; MS: Mass spectrometer; $\mathrm{m} / \mathrm{z}$ : Mass-to-charge ratio; OVA: Ovalbumin; OVX: Ovariectomized; PE: Phycoerythrin;

RA: Rheumatoid arthritis; St6gal1: $\beta$-Galactoside a2,6-sialyltransferase 1; TNF: Tumor necrosis factor

\section{Acknowledgements}

We acknowledge excellent assistance provided by Silke Winkler, Wolfgang Baum, Merja Nurkkula- Karlsson, Katharina Falk, Petra Henning, and Marcus Söderberg. We also thank Holger Bang (Orgentec Diagnostika) for providing ACPA tests used in the project.

\section{Funding}

This study was supported by the Swedish Research Council (537-2013-7370), Deutsche Forschungsgemeinschaft (SPP1468 Immunobone and CRC 1181), the Bundesministerium für Bildung und Forschung (BMBF; METARTHROS), the Marie-Curie Project Osteoimmune, the TEAM project of the European Union, the IMI-funded project RTCure, the Swedish Association for Medical Research, the Interdisciplinary Centre for Clinical Research of the University of Erlangen-Nuremberg, Cancerfonden, Konung Gustav $\vee$ stiftelse, and Åke Wiberg stiftelse.

\section{Availability of data and materials}

The dataset used and analyzed during the present study are available from the corresponding author on reasonable request.

\section{Authors' contributions}

CE and GS designed the study. CE, JR, UH, and RP performed animal experiments and cell cultivation experiments and interpreted the data. $A B$ performed mass spectrometry measurements. AB, MW, and HUS interpreted 
data and provided expertise and input. AC and ILMB performed the human cell cultivation, interpreted data, and provided expertise. MS and FN provided the antibodies for Fcy receptors, interpreted data, and provided expertise. HFd'E performed the study with the postmenopausal patients with RA, interpreted data, and provided expertise. CE, GK, HFd'E, and GS provided expertise and input all data together. CE, UH, and GS wrote the manuscript. All authors critically reviewed the manuscript. All authors read and approved the final manuscript.

\section{Ethics approval and consent to participate}

Animal studies were approved by the ethics committees of the Government of Mittelfranken, Germany, and University of Gothenburg, Sweden. All patients gave informed consent, and the ethics committee at the University of Gothenburg (Sweden) approved the study.

\section{Competing interests}

The authors declare that they have no competing interests.

\section{Publisher's Note}

Springer Nature remains neutral with regard to jurisdictional claims in published maps and institutional affiliations.

\section{Author details}

'Department of Internal Medicine 3, Rheumatology and Immunology, Universitätsklinikum Erlangen, Friedrich Alexander University Erlangen-Nürnberg, Erlangen, Germany. ${ }^{2}$ Department of Rheumatology and Inflammation Research, Institute of Medicine, University of Gothenburg, Gothenburg, Sweden. ${ }^{3}$ Centre for Bone and Arthritis Research, Department of Internal Medicine and Clinical Nutrition, Institute of Medicine, University of Gothenburg, Gothenburg, Sweden. ${ }^{4}$ Department of Rheumatology, Leiden University Medical Center, Leiden, The Netherlands. ${ }^{5}$ Center for Proteomics and Metabolomics, Leiden University Medical Center, Leiden, The Netherlands. ${ }^{6}$ Institute of Genetics at the Department of Biology, FAU Erlangen-Nuremberg, Erlangen, Germany. ${ }^{7}$ Department of Public Health and Clinical Medicine, Umeå University, Umeå, Sweden.

Received: 17 January 2018 Accepted: 3 April 2018

Published online: 02 May 2018

\section{References}

1. Goemaere S, Ackerman C, Goethals K, De Keyser F, Van der Straeten C, Verbruggen G, Mielants H, Veys EM. Onset of symptoms of rheumatoid arthritis in relation to age, sex and menopausal transition. J Rheumatol. 1990;17(12):1620-2.

2. Brennan P, Bankhead C, Silman A, Symmons D. Oral contraceptives and rheumatoid arthritis: results from a primary care-based incident case-control study. Semin Arthritis Rheum. 1997;26(6):817-23.

3. Mclnnes IB, Schett $G$. The pathogenesis of rheumatoid arthritis. N Engl J Med. 2011:365(23):2205-19.

4. Catrina Al, Svensson Cl, Malmstrom V, Schett G, Klareskog L. Mechanisms leading from systemic autoimmunity to joint-specific disease in rheumatoid arthritis. Nat Rev Rheumatol. 2017;13(2):79-86.

5. Malmström V, Catrina Al, Klareskog L. The immunopathogenesis of seropositive rheumatoid arthritis: from triggering to targeting. Nat Rev Immunol. 2017;17(1):60-75

6. Rantapaa-Dahlqvist S, de Jong BA, Berglin E, Hallmans G, Wadell G, Stenlund $H$, Sundin U, van Venrooij WJ. Antibodies against cyclic citrullinated peptide and IgA rheumatoid factor predict the development of rheumatoid arthritis. Arthritis Rheum. 2003;48(10):2741-9.

7. Berglin E, Padyukov L, Sundin U, Hallmans G, Stenlund H, Van Venrooij WJ, Klareskog L, Dahlqvist SR. A combination of autoantibodies to cyclic citrullinated peptide (CCP) and HLA-DRB1 locus antigens is strongly associated with future onset of rheumatoid arthritis. Arthritis Res Ther. 2004; 6(4):R303-8

8. Svensson L, Jirholt J, Holmdahl R, Jansson L. B cell-deficient mice do not develop type II collagen-induced arthritis (CIA). Clin Exp Immunol. 1998; 111(3):521-6.

9. Kleinau S, Martinsson P, Heyman B. Induction and suppression of collageninduced arthritis is dependent on distinct fcgamma receptors. J Exp Med. 2000;191(9):1611-6.
10. Holmdahl R, Rubin K, Klareskog L, Larsson E, Wigzell H. Characterization of the antibody response in mice with type II collagen-induced arthritis, using monoclonal anti-type II collagen antibodies. Arthritis Rheum. 1986;29(3):400-10.

11. Nimmerjahn F, Ravetch JV. Antibody-mediated modulation of immune responses. Immunol Rev. 2010;236:265-75.

12. Yamaguchi $Y$, Nishimura M, Nagano $M$, Yagi $H$, Sasakawa $H$, Uchida $K$, Shitara K, Kato K. Glycoform-dependent conformational alteration of the Fc region of human immunoglobulin G1 as revealed by NMR spectroscopy. Biochim Biophys Acta. 2006;1760(4):693-700.

13. Dekkers G, Treffers L, Plomp R, Bentlage AEH, de Boer M, Koeleman CAM, Lissenberg-Thunnissen SN, Visser R, Brouwer M, Mok JY, et al. Decoding the human immunoglobulin G-glycan repertoire reveals a spectrum of Fcreceptor- and complement-mediated-effector activities. Front Immunol. 2017:8:877.

14. Parekh RB, Dwek RA, Sutton BJ, Fernandes DL, Leung A, Stanworth D, Rademacher TW, Mizuochi T, Taniguchi T, Matsuta K, et al. Association of rheumatoid arthritis and primary osteoarthritis with changes in the glycosylation pattern of total serum lgG. Nature. 1985;316(6027):452-7.

15. Rademacher TW, Williams P, Dwek RA. Agalactosyl glycoforms of IgG autoantibodies are pathogenic. Proc Natl Acad Sci U S A. 1994;91(13): 6123-7.

16. Hess C, Winkler A, Lorenz AK, Holecska V, Blanchard V, Eiglmeier S, Schoen AL, Bitterling J, Stoehr AD, Petzold D, et al. T cell-independent B cell activation induces immunosuppressive sialylated lgG antibodies. J Clin Invest. 2013;123(9):3788-96.

17. Ito K, Furukawa J, Yamada K, Tran NL, Shinohara Y, Izui S. Lack of galactosylation enhances the pathogenic activity of lgG1 but Not lgG2a anti-erythrocyte autoantibodies. J Immunol. 2014;192(2):581-8.

18. Ohmi Y, Ise W, Harazono A, Takakura D, Fukuyama H, Baba Y, Narazaki M, Shoda H, Takahashi N, Ohkawa Y, et al. Sialylation converts arthritogenic lgG into inhibitors of collagen-induced arthritis. Nat Commun. 2016;7:11205.

19. Bohm S, Schwab I, Lux A, Nimmerjahn F. The role of sialic acid as a modulator of the anti-inflammatory activity of $\mathrm{lgG}$. Semin Immunopathol. 2012;34(3):443-53.

20. Pfeifle R, Rothe T, Ipseiz N, Scherer HU, Culemann S, Harre U, Ackermann JA, Seefried M, Kleyer A, Uderhardt S, et al. Regulation of autoantibody activity by the IL-23-TH 17 axis determines the onset of autoimmune disease. Nat Immunol. 2017:18:104-13.

21. Rombouts $Y$, Ewing $E$, van de Stadt LA, Selman MH, Trouw LA, Deelder AM, Huizinga TW, Wuhrer M, van Schaardenburg D, Toes RE, et al. Anticitrullinated protein antibodies acquire a pro-inflammatory Fc glycosylation phenotype prior to the onset of rheumatoid arthritis. Ann Rheum Dis. 2015; 74(1):234-41.

22. Chen G, Wang Y, Qiu L, Qin X, Liu H, Wang X, Wang Y, Song G, Li F, Guo Y, et al. Human IgG Fc-glycosylation profiling reveals associations with age, sex, female sex hormones and thyroid cancer. J Proteome. 2012;75(10):2824-34.

23. Bakovic MP, Selman MH, Hoffmann M, Rudan I, Campbell H, Deelder AM, Lauc G, Wuhrer M. High-throughput lgG Fc N-glycosylation profiling by mass spectrometry of glycopeptides. J Proteome Res. 2013;12(2):821-31.

24. Bondt A, Selman MH, Deelder AM, Hazes JM, Willemsen SP, Wuhrer M, Dolhain RJ. Association between galactosylation of immunoglobulin $\mathrm{G}$ and improvement of rheumatoid arthritis during pregnancy is independent of sialylation. J Proteome Res. 2013;12(10):4522-31.

25. van de Geijn FE, Wuhrer M, Selman MH, Willemsen SP, de Man YA, Deelder AM, Hazes JM, Dolhain RJ. Immunoglobulin G galactosylation and sialylation are associated with pregnancy-induced improvement of rheumatoid arthritis and the postpartum flare: results from a large prospective cohort study. Arthritis Res Ther. 2009;11(6):R193.

26. Ercan A, Kohrt WM, Cui J, Deane KD, Pezer M, Yu EW, Hausmann JS, Campbell H, Kaiser UB, Rudd PM, et al. Estrogens regulate glycosylation of lgG in women and men. JCI Insight. 2017;2(4):e89703.

27. Nilsson ME, Vandenput L, Tivesten A, Norlen AK, Lagerquist MK, Windahl SH, Borjesson AE, Farman $\mathrm{HH}$, Poutanen M, Benrick A, et al. Measurement of a comprehensive sex steroid profile in rodent serum by high-sensitive gas chromatography-tandem mass spectrometry. Endocrinology. 2015;156(7): 2492-502.

28. Offner H, Adlard K, Zamora A, Vandenbark AA. Estrogen potentiates treatment with T-cell receptor protein of female mice with experimental encephalomyelitis. J Clin Invest. 2000;105(10):1465-72.

29. D'Elia HF, Larsen A, Mattsson LA, Waltbrand E, Kvist G, Mellstrom D, Saxne T, Ohlsson C, Nordborg E, Carlsten H. Influence of hormone replacement 
therapy on disease progression and bone mineral density in rheumatoid arthritis. J Rheumatol. 2003;30(7):1456-63.

30. Arnett FC, Edworthy SM, Bloch DA, McShane DJ, Fries JF, Cooper NS, Healey LA, Kaplan SR, Liang MH, Luthra HS, et al. The American Rheumatism Association 1987 revised criteria for the classification of rheumatoid arthritis. Arthritis Rheum. 1988:31(3):315-24.

31. Jansen BC, Falck D, de Haan N, Hipgrave Ederveen AL, Razdorov G, Lauc G, Wuhrer M. LaCyTools: a targeted liquid chromatography-mass spectrometry data processing package for relative quantitation of glycopeptides. J Proteome Res. 2016;15(7):2198-210.

32. Ralston SH, Russell RG, Gowen M. Estrogen inhibits release of tumor necrosis factor from peripheral blood mononuclear cells in postmenopausal women. J Bone Miner Res. 1990;5(9):983-8.

33. Croce A, Firuzi O, Altieri F, Eufemi M, Agostino R, Priori R, Bombardieri M, Alessandri C, Valesini G, Saso L. Effect of infliximab on the glycosylation of IgG of patients with rheumatoid arthritis. J Clin Lab Anal. 2007;21(5):303-14.

34. D'Elia HF, Mattsson LA, Ohlsson C, Nordborg E, Carlsten H. Hormone replacement therapy in rheumatoid arthritis is associated with lower serum levels of soluble IL-6 receptor and higher insulin-like growth factor 1 . Arthritis Res Ther. 2003;5(4):R202-9.

35. d'Elia HF, Carlsten $\mathrm{H}$. The impact of hormone replacement therapy on humoral and cell-mediated immune responses in vivo in post-menopausal women with rheumatoid arthritis. Scand J Immunol. 2008;68(6):661-7.

36. McInnes IB, Schett G. Pathogenetic insights from the treatment of rheumatoid arthritis. Lancet. 2017;389(10086):2328-37.

37. Masuzawa T, Miyaura C, Onoe Y, Kusano K, Ohta H, Nozawa S, Suda T. Estrogen deficiency stimulates B lymphopoiesis in mouse bone marrow. J Clin Invest. 1994;94(3):1090-7.

38. Erlandsson MC, Jonsson CA, Islander U, Ohlsson C, Carlsten H. Oestrogen receptor specificity in oestradiol-mediated effects on $\mathrm{B}$ lymphopoiesis and immunoglobulin production in male mice. Immunology. 2003;108(3):346-51.

39. Hill L, Jeganathan V, Chinnasamy P, Grimaldi C, Diamond B. Differential roles of estrogen receptors alpha and beta in control of B-cell maturation and selection. Mol Med. 2011;17(3-4):211-20

40. Verthelyi DI, Ahmed SA. Estrogen increases the number of plasmablasts and enhances their autoantibody production in nonautoimmune C57BL/6 mice. Cell Immunol. 1998;189(2):125-34.

41. Grimaldi CM, Jeganathan V, Diamond B. Hormonal regulation of B cell development: 17 beta-estradiol impairs negative selection of high-affinity DNA-reactive B cells at more than one developmental checkpoint. J Immunol. 2006;176(5):2703-10.

42. Ostensen M, Aune B, Husby G. Effect of pregnancy and hormonal changes on the activity of rheumatoid arthritis. Scand J Rheumatol. 1983;12(2):69-72.

43. Colangelo K, Haig S, Bonner A, Zelenietz C, Pope J. Self-reported flaring varies during the menstrual cycle in systemic lupus erythematosus compared with rheumatoid arthritis and fibromyalgia. Rheumatology (Oxford). 2011;50(4):703-8.

\section{Ready to submit your research? Choose BMC and benefit from:}

- fast, convenient online submission

- thorough peer review by experienced researchers in your field

- rapid publication on acceptance

- support for research data, including large and complex data types

- gold Open Access which fosters wider collaboration and increased citations

- maximum visibility for your research: over $100 \mathrm{M}$ website views per year

At BMC, research is always in progress.

Learn more biomedcentral.com/submissions 